\section{Parque Anhembi: Entre Mercantilização da Imagem Urbana, Patrimônio Cultural e Privatização}

\section{ANHEMBI PARK: Between Urban Image Commodification, Cultural Heritage and Privatization}

\section{Resumo}

O artigo procura resgatar a história da implantação do Parque Anhembi como meio "técnico" usado no processo de metropolização da capital paulista, incentivador da industrialização, ao lado do plano de desenvolvimento nacional, em seu papel da construção de uma imagem de cidade moderna e na inserção da cidade como importante polo de negócios nacional e internacional. São avaliados os mecanismos legais ou aparatos criados para a sua realização e gestão. Por fim, são apontados alguns caminhos para se entender o embate entre preservação e privatização do conjunto, as inversões sobre o entendimento de instrumentos importantes para a salvaguarda de bens patrimoniais e a reflexão sobre os caminhos da gestão da cidade quando não são toleráveis interesses divergentes.

Palavras-Chave: Parque Anhembi, História da Arquitetura Moderna, Patrimônio Cultural, Mercantilização, Privatização.

\section{Abstract \\ The article seeks to rescue Anhembi Park implantation history as a "technical" medium used in the process of establishing the capital of São Paulo State as a metropolis, an incentive for industrialization, alongside the national development plan, in its role of building a modern city image and its insertion as an important national and international business pole. Legal mechanisms or apparatuses created for such achievement and management are evaluated. Finally, some ways are pointed out to understand the conflict between its preservation}

Prof. ${ }^{a}$ Dr. ${ }^{a}$. Raíssa Pereira Cintra de Oliveira

Doutora pela FAU-USP em Teoria e Fundamentos da Arquitetura e Urbanismo; atualmente é Professora de Projeto e Desenho no UNASP-EC,

Email: raissapereiracintra@ gmail.com 
and privatization, the inversions on important tools understanding about the safeguarding of patrimonial assets and the reflection on city management choices when different interests are not considered.

Keywords: Anhembi Park, History of Modern Architecture, Cultural Heritage, Merchantilization, Privatization

Esse texto tem como fonte inspiradora a reflexão acerca do episódio de aprovação do pacote de privatização e concessão de bens e serviços públicos ocorrido em 2017 na prefeitura de São Paulo, quando houve, então, disputas de interesse sobre algumas áreas tombadas, como o Estádio do Pacaembu e o Jockey Club, por exemplo, e outras, ainda em processo de tombamento, como é o caso do Parque Anhembi. O texto se restringe ao processo do Parque Anhembi, dentro de uma ótica ampliada sobre o projeto e sua implantação, buscando identificar as principais razões e conflitos existentes nesse embate, que redirecionam nosso olhar para os meios de gestão da cidade, em especial sobre predominância dos interesses especulativos na sua história até os dias de hoje.

Procura-se, então, recuperar a história da implantação do centro de exposições, num primeiro momento, entendendo o Parque Anhembi como meio técnico (SANTOS, 1995, p. 18) usado no processo de metropolização, incentivador da industrialização em São Paulo ao lado do plano de desenvolvimento nacional - tanto na invenção desse "objeto técnico" ligado a uma grande escala antes inexistente, como também no seu papel na construção de uma imagem de cidade industrializada e disposta a inserir-se como importante polo de negócios nacional e internacional. Imagem de uma metrópole emprestada para apresentar outro Brasil moderno, industrial, desenvolvido e, sobretudo, diverso da imagem exótica, plástica e branca divulgada mundo afora pelas imagens de Brasília - a qual já demostraria focos polêmicos de discussão instigados pelos canteiros de obra "irracionais" e "violentos" (GIEDION, 1952; FERRO, 1976).
Em outras palavras, seja nos mecanismos legais ou aparatos criados para a sua realização e gestão, é possivel entender a pré- visualização, defendida antes mesmo da sua implantação, como um traço que marca a hegemonia de determinados agentes empreendedores na produção da cidade e o interesse do Estado em empreendimentos de grande vulto relacionados à produção da infraestrutura necessária para atingir o desenvolvimento do país. Ainda sobre uma perspectiva territorial, mas analisando outra escala, percebe-se sua implantação como meio de produção e reprodução da cidade, no processo de ocupação urbana da Zona Norte da capital paulista, das margens ainda disponíveis do Rio Tietê e, ainda, na afirmação da importância dos fluxos de transportes que se afirmariam em todas as suas escalas naquele local.

Num segundo momento, o texto aborda o objeto dentro da importância das inovações programáticas e tecnológicas propostas, das experimentações técnicas, construtivas, formais e arquitetônicas ou da modificação da prática profissional, abrindo o caminho, então, para a verificação, num mesmo objeto, de características canonizadas sobre a arquitetura das décadas de 1960 e 1970 pela historiografia da arquitetura. A partir dessa visão do complexo, é possivel refletir sobre o seu valor cultural na sociedade, dentro de uma perspectiva alargada, que vai além do entendimento desse objeto como testemunho material da arquitetura moderna desse período, mas que o insere como documento material representativo dos traços sociais, econômicos e históricos desse momento de nosso país. Fica, então, a chancela sobre uma discussão (que nunca foi possivel acontecer) que ilumina o questionamento sobre o valor do objeto de modo mais ampliado e que poderia ser enriquecedora durante o tombamento iniciado pelo Conselho Municipal de Preservação do Patrimônio Histórico, Cultural e Ambiental da Cidade de São Paulo (Conpresp) em 2004, porém indeferido em 2017. 
Por fim, é relevante analisar o embate entre preservação e privatização neste processo, uma vez que transtornos ou inversões sobre o entendimento de instrumentos importantes para a gestão da cidade são evidenciados com clareza nos discursos, instigando uma urgente ação dentro da gestão urbana - evidente sobretudo no entendimento do tombamento como meio de "desvalorização". Além disso, o momento das justificativas sobre o arquivamento do processo de tombamento do Parque Anhembi dá início a um perigoso caminho para as políticas de preservação em geral, não apenas para os conjuntos arquitetônicos, mas para o próprio entendimento da necessidade de preservação dos meios materiais ou, melhor dizendo, da existência desses testemunhos vivos na paisagem urbana da cidade.

\section{Mercantilização da imagem da cidade e do turismo}

Não há dúvida de que durante a idealização do Parque Anhembi, nos meios de implantação e divulgação deste empreendimento, já existiam indícios sobre os principais agentes empreendedores na produção da cidade naquele momento. A começar pelo principal personagem da sua idealização e viabilização, Caio de Alcântara Machado (1926-2003), empresário ligado à área de marketing e publicidade e que na década de 1950 iniciaria a sua carreira promovendo a imagem do Brasil nas grandes feiras mundiais ligadas à produção dos países industrializados, como a US World Trade Fair, em 1957, por exemplo. Segundo depoimento do próprio publicitário (SPTuris, 1970), como o Brasil ainda não era um país industrializado, a exposição se detinha na imagem moderna de Brasília e seguindo à risca a agenda de Juscelino Kubitschek. Algumas imagens encontradas na revista Brasília comprovam o conteúdo exposto nestas feiras por ele organizadas: basicamente, imagens dos projetos de Brasília, maquetes, textos e mapas.
Fig. 1 Fotos do Pavilhão Brasileiro na US World Trade Fair, em Nova York (o ministro Jayme Chermint e a cantora lírica Bidu Sayão no local onde se veem alguns projetos de Oscar Niemeyer.

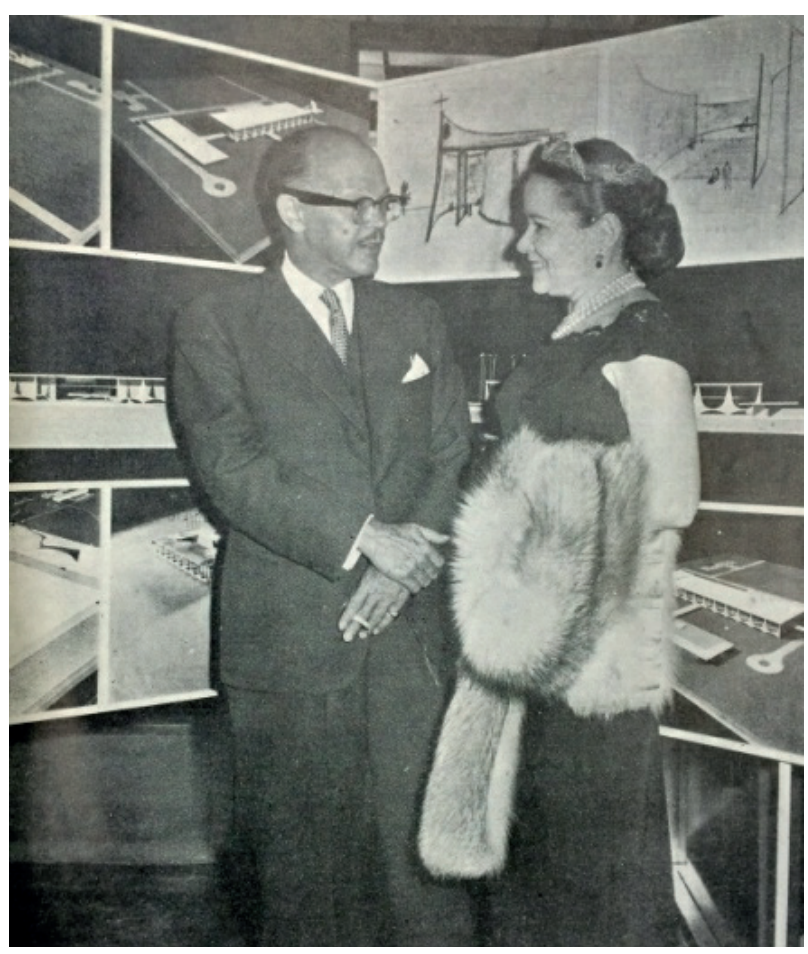

Fonte: Brasília (revista da Companhia Urbanizadora da Nova Capital), n. 20, 1960, pp. 14-5.

À imagem do país campeão do mundo na Copa de 1958 e à de uma nação moderna revelada na construção da sua nova capital federal, somava-se, então, a imagem de um país desenvolvido e industrializado. Em menos de dez anos realizando feiras de negócios em São Paulo, como a Fenit, a Feira de Utilidades Domésticas, o Salão do Automóvel e o Salão da Criança, Caio de Alcântara Machado começou a almejar outro espaço maior que o Pavilhão das Indústrias do Parque do Ibirapuera. E a aceleração da producão industrial no país era justificativa para as feiras, sobretudo pelos índices do crescimento da indústria automobilística e pela produção de aço; assim, não por acaso, o VII Salão do Automóvel inauguraria em 1968 o novo palco para o turismo de negócios: um pavilhão metálico de grandes proporções chamado de Pavilhão de Exposições do Parque Anhembi. 
Na pesquisa de doutoramento "Parque Anhembi: a produção de um centro de exposições em São Paulo (1963-1972)" (Oliveira, 2016), foi possível investigar com profundidade os discursos de idealização e de promoção do projeto. Entrevistas, reportagens de revistas da época ou periódicos promocionais das empresas envolvidas na construção do centro de exposicões, anúncios em jornais de grande circulação, plantas aprovadas, vídeos promocionais, fotos, cartas, mapas e outros documentos formam uma trama que comprovam a manipulação das imagens do projeto e da cidade, seguindo por uma seleção cirúrgica para cada propósito e modos de convencimento. Percebe-se, por exemplo, a forma como o empresariado angariou um terreno público através da concessão de 40 anos e que dispunha de contrapartidas jamais realizadas pelo interesse privado.

Os termos da Lei n. 7085 de 12 de dezembro de 1967 previam em troca dos anos de exploração do terreno das empresas promotoras de feiras "[...] construir recinto cívico, museu, restaurante e confeitaria, bancas de jornais, revistas, flâmulas e similares, parque público com áreas de recreação ativa (playground, etc.) e contemplativa (espelho d'água, jardins, monumentos cívicos, etc.)". E nesse processo, há que se considerar que no meio da construção do conjunto e após finalizada a obra do Pavilhão de Exposições (principal objeto de interesse dos empresários vinculados no conjunto do Parque Anhembi), o próprio Estado acabou se tornando acionista majoritário e tomava para si grande parte da responsabilidade de sua finalização e gestão. Todo o contexto ilustrado por imagens de uma cidade longe do caos urbano do centro da capital, em meio às montanhas da Zona Norte, com seus jardins à margem do Rio Tietê, conforma um desenho de uma cidade moderna e acessível e, ainda, ofertando um novo espaço público voltado à população.

Fig. 2. Página dupla de jornais de grande circulação convidando para a inauguração da obra do Parque Anhembi, onde o Pavilhão de Exposições é desfocado da imagem.

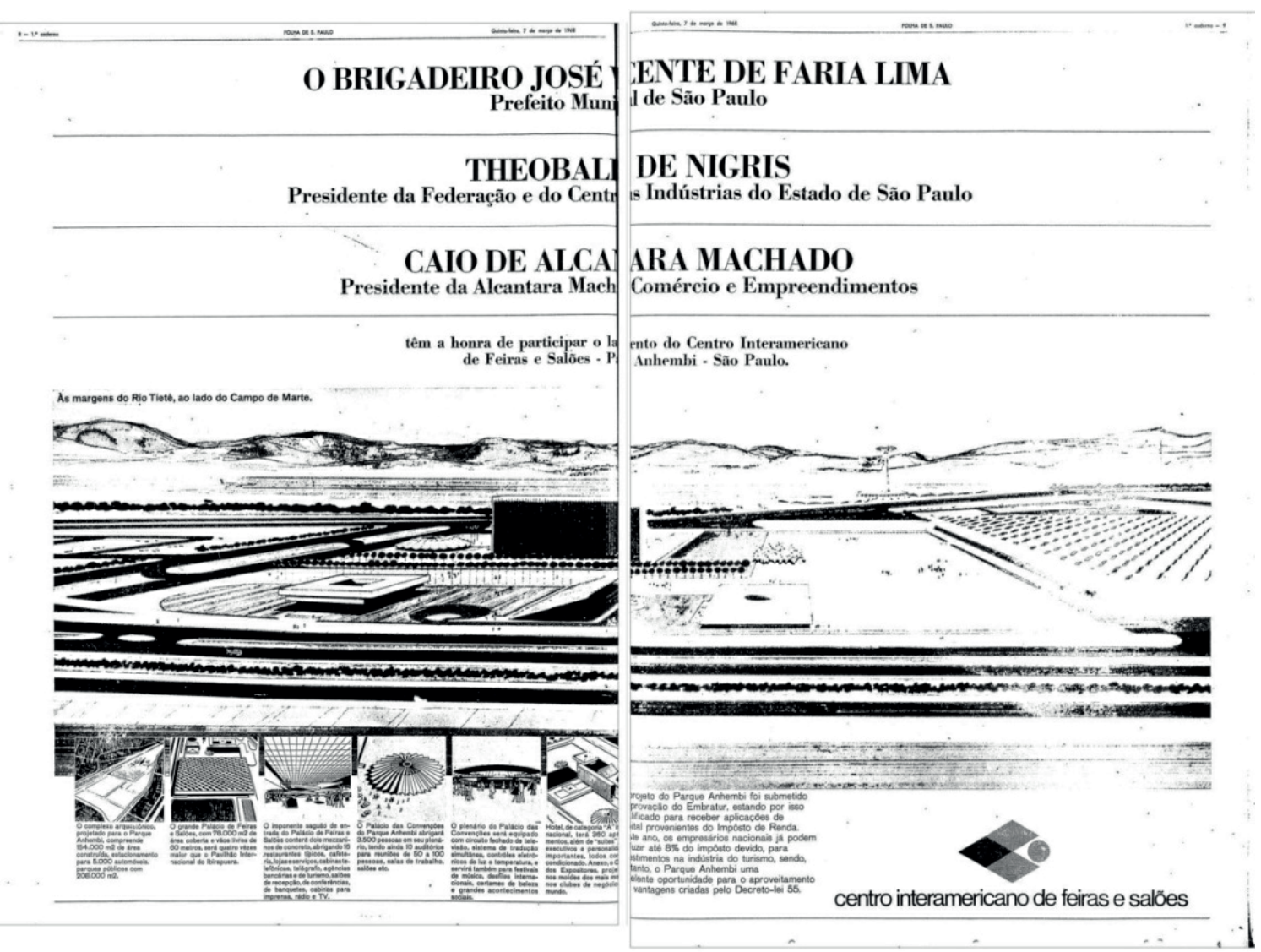

Fontes: Folha de S. Paulo,10 de março de 1968; O Estado de S. Paulo, 07 de março de 1968. 
Também o foco proposto para o novo padrão do turismo, chamado "turismo de negócios", aqui se concretiza principalmente pela imagem do conjunto Palácio-Hotel. Foco este utilizado na estratégia de financiamento da obra fazendo-se uso de meios legais de aprovação, e que simplesmente transformam o escopo do empreendimento em um "Complexo Hoteleiro", modificando intencionalmente o escopo da proposta de forma a permitir a aprovação do projeto como um dos primeiros financiados pela EMBRATUR, verba esta que seria destinada à promoção do turismo nas regiões Norte e Nordeste do país (Decreto Lei 55 de novembro de 1966).

Fig. 3. Carimbo padrão das plantas da área da praça, edifícios públicos contidos nela, do Palácio das Convenções e Hotel aprovadas e intituladas "Complexo Turístico Hoteleiro Parque Anhembi”.

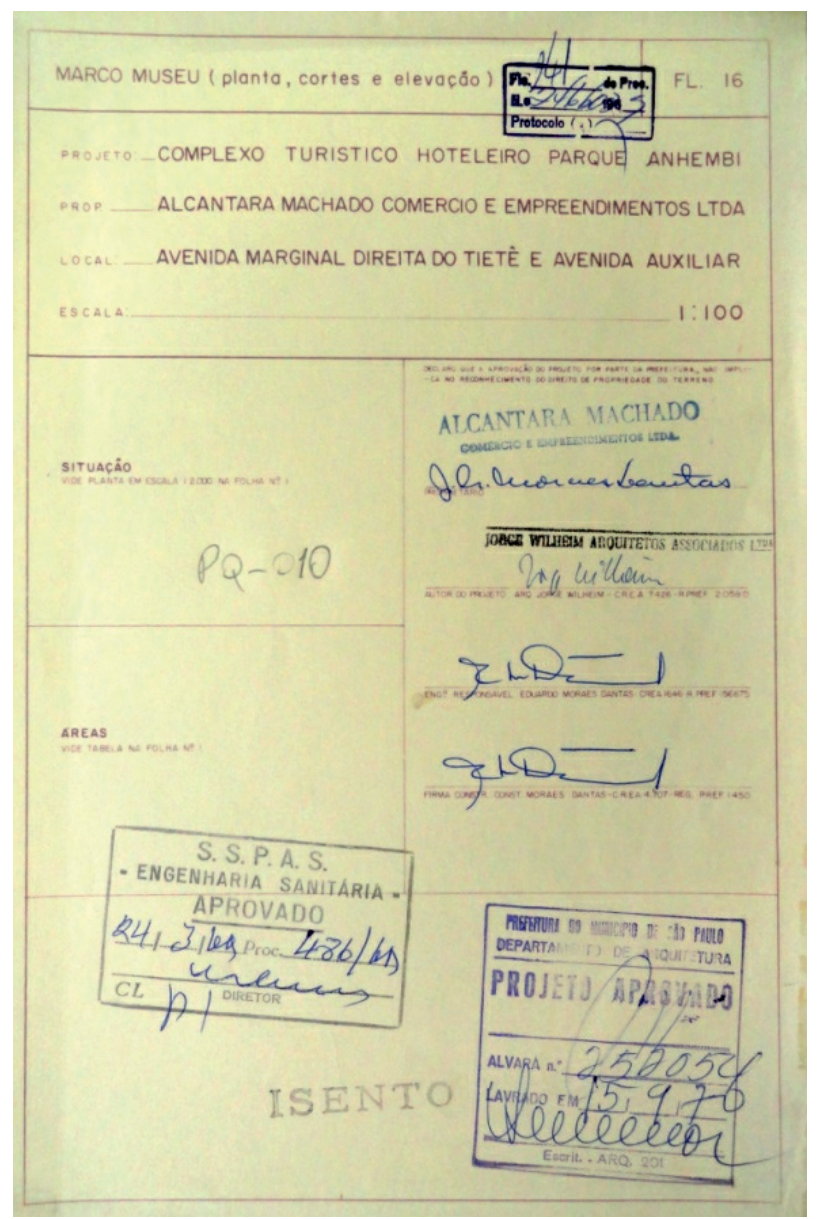

Fonte: arquivo da Diretoria de Infraestrutura da São Paulo Turismo.
A finalização do objetivo de Caio de Alcântara Machado só foi possível mediante empréstimos em bancos internacionais e participação de vários bancos nacionais consorciados para a operação de repasse, o que significou um marco para as táticas operacionais de investimentos no Brasil e na modernização das instituições bancárias (BETING, 1970). A própria ajuda "extra" não planejada por ele no início da obra acabou ganhando um tom estrategista, um discurso de convencimento da aplicação do investimento no negócio que obtinha o "aval de instituições e empresas idôneas", como os bancos internacionais. Nesse período, conhecido como a época do "milagre econômico", o governo militar investia em obras faraônicas de infraestrutura, como a Transamazônica (1972) e a Ponte Rio-Niterói (1968-1974), por exemplo, por meio de empréstimos vindos do exterior. Portanto, acredita-se que o processo de financiamento do capital estrangeiro usado para obter fundos na construção do Parque Anhembi foi pioneiro.

Nesta perspectiva, o empreendimento ganha um vulto público característico das grandes obras empreendidas pelo governo militar daquela época, e tomando-se a data do início da obra como parâmetro de análise, julho de 1968, a sua construção coincide com as greves sindicais e o endurecimento do regime militar. Também a "ideia" da sua finalização divulgada em jornais de grande circulação (porque não foi executada dentro da totalidade do projeto), significaria também a construção da imagem de "eficiência" de todos os enredados, inclusive pelo regime militar.

Dessa forma, nota-se que a obra, na fala articulada dos meios de divulgação em massa, era usada como discurso publicitário pró-governo. A inauguração do Parque Anhembi, por exemplo, com a abertura do VII Salão do Automóvel, principal indústria favorecida nesse período, associava o evento e o local do evento aos objetivos políticos nacionais de industrialização e desenvolvimento ou, em alguns momentos, às ações desses distintos planos de interesses, dos promotores das feiras, dos 
empresários e do governo. E esses planos de interesses são alinhados como parte de um discurso promocional único nacional, vinculado ao processo de industrialização e construção dos meios técnicos favoráveis a esse objetivo, como o título da publicação já indica: "O maior Palácio de Exposições das Américas está no mesmo país que faz a Transamazônica".

Fig. 4. O grande feito de São Paulo, o "maior" Pavilhão de Exposições das Américas, é colocado ao lado da maior obra de infraestrutura do governo federal, a

Transamazônica, naquele momento uma obra promissora para

o desenvolvimento do país, e artigo usando o

discurso do retorno do investimento.
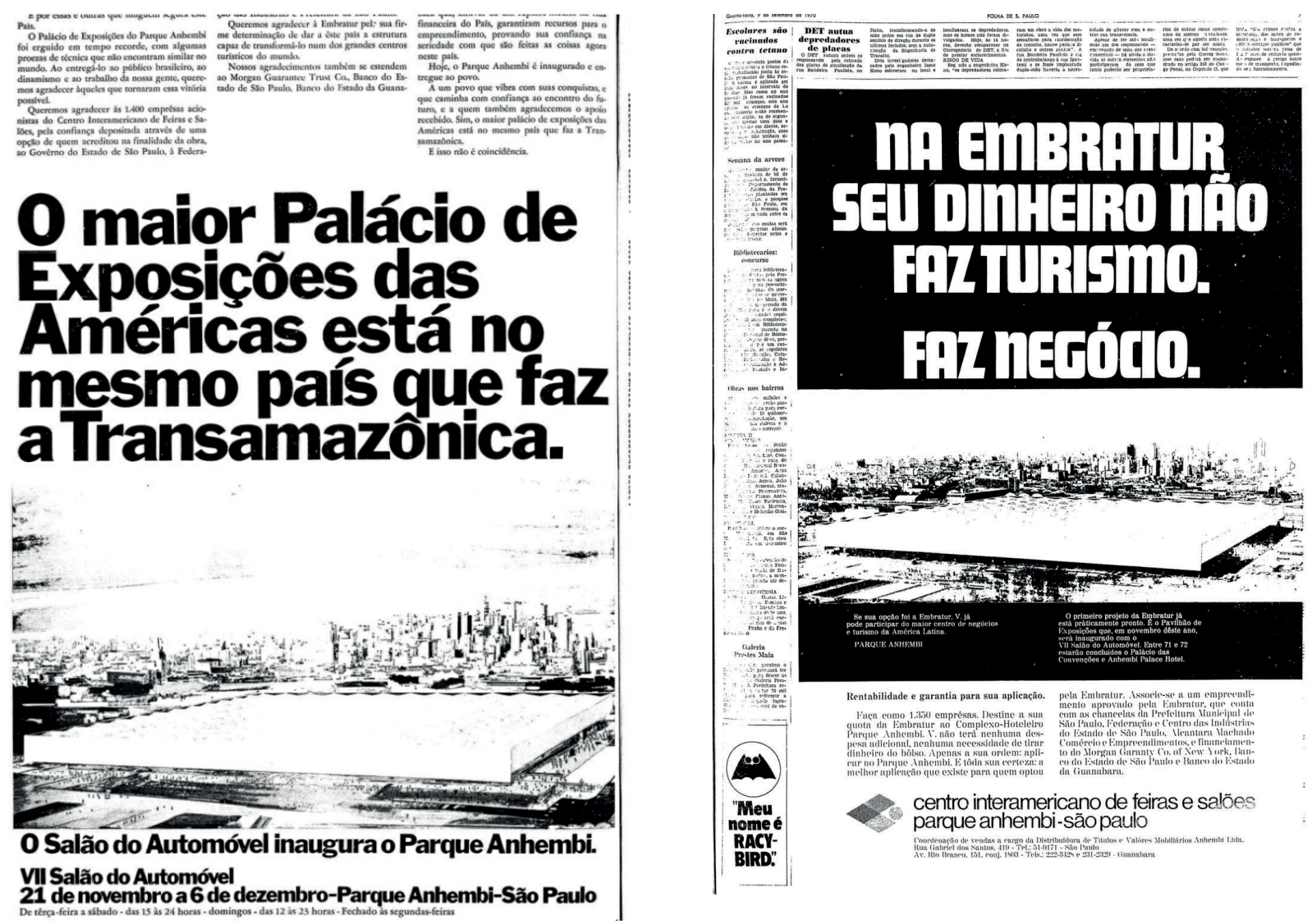

Fontes: Folha de S. Paulo, 19 de novembro de 1970; Folha de S. Paulo, 03 de maio de 1970. A mesma campanha saiu no jornal do dia 16 de novembro de 1970 e 14 de outubro de 1970.

O texto tem um tom inaugural da obra como se ela já tivesse sido finalizada completamente: "Hoje o Parque Anhembi é inaugurado e entregue ao povo". Esse "êxito", promulgado com frequência nos textos, só teria sido possivel dentro de um alto grau de desenvolvimento do país, discurso esse que se utilizaria também das imagens do canteiro de obras do Pavilhão de Exposições, excepcional, se comparado à massa das construções e meios sociotécnicos existentes então na construção civil. Vinculado à industrializacão e "erguido em tempo recorde, com algumas proezas técnicas que não encontram similar no mundo" (JOTA PRODUÇÕES, 1970), o Pavilhão de Exposições se tornava o símbolo da construção civil nacional.

\section{Relevância do objeto dentro da historiografia da arquitetura e de outras histórias}

A construção do programa do complexo revela também o papel de São Paulo como centro 
das novas realidades técnicas no país, num sentido amplo da palavra "técnica", conforme indica Milton Santos: "não apenas as técnicas da vida material, mas todas as técnicas de que o homem se vale para produzir e reproduzir a sociedade" (1995, p. 18), ou seja, os sistemas técnicos sob os quais nos tornamos dependentes de uma forma muitas vezes desapercebida e articulada nas tarefas do dia a dia e que vêm modificar todas as formas de convivialidade. Afinal, a demanda inicial de Caio de Alcântara Machado era apenas uma cobertura para abrigar um espaço "4 vezes maior que o Pavilhão do Ibirapuera" (REVISTA VEJA, 1970). No entanto, a encomenda é direcionada a um profissional arquiteto urbanista, Jorge Wilheim, envolvido com atividades formadoras de opinião e com o tema urbano.

A contribuição específica do arquiteto urbanista configura-se como objeto de estudo de grande relevância, em primeiro lugar, porque a atuação dos arquitetos urbanistas como objeto de estudo neste período é um tema colocado em pauta, já que, segundo se observa, é uma prática profissional que sente com mais rapidez a necessidade de enfrentar uma nova realidade, principalmente, a de outra escala, a metropolitana (PEDROSA, 1960). Em segundo lugar, porque ainda que a geração profissional de Jorge Wilheim seja razoavelmente heterogênea, a particularidade da sua própria atuação parece apontar os círculos sociais não desprezíveis para o entendimento da proeminência dos arquitetos paulistas neste momento no cenário nacional (DEDECCA, 2012) e, neste caso específico, da ênfase no tema urbano em sua atuação.

A historiografia da arquitetura do período em estudo evidencia a recorrência do peso da questão urbana e construtiva que permearia as preocupações nas pranchetas dos arquitetos dessa geração (OLIVEIRA, 2016b) e o escritório do arquiteto urbanista seria um exemplo extremo (mas ao mesmo tempo único) quando o foco é a questão urbana, principalmente, se se considerar que projetos de planejamento urbano de grande envergadura partiriam de uma condição liberal de trabalho. Ao apoiar-se numa visão mais ampla das dinâmicas históricas, sociais e econômicas da cidade (WILHEIM, 1965) e, consequentemente, das carências técnicas disponíveis em seu território dentro da escala de uso das massas - como a própria característica deste turismo específico se daria (uma massa de pessoas vindas de locais diversos para um mesmo lugar ao mesmo tempo), o arquiteto configuraria a tríade básica do programa do conjunto: Pavilhão-Convenções-Hotel.

A construção do programa do Parque Anhembi desponta estas histórias reveladoras da escala metropolitana também no âmbito cotidiano da atuação profissional como problema, e com isso surgem novas condutas dessa prática. Jorge Wilheim cria no projeto do Parque Anhembi formas de estruturar a produção de um espaço público na cidade de São Paulo, seja pelas escolhas formais, pelos partidos arquitetônicos escolhidos, participando do convencimento do cliente e do Estado, fazendo articulações espaciais no projeto arquitetônico e urbanístico (principalmente na presença da área verde como articulador dos volumes), criando mecanismos legais de gestão do empreendimento e o próprio gerenciamento de uma equipe interdisciplinar especializada, cada qual dotando o projeto de suas contribuições e, deste modo, configurando uma atuação não autônoma perante o projeto e a obra.

Fig. 5. Maquete do projeto do Parque Anhembi com interferências da autora desse artigo.

1- Pavilhão de Exposições; 2- Hotel (bloco horizontal e vertical); 3- Palácio das Convenções;

\section{4- Praça; 5- Estacionamento.}

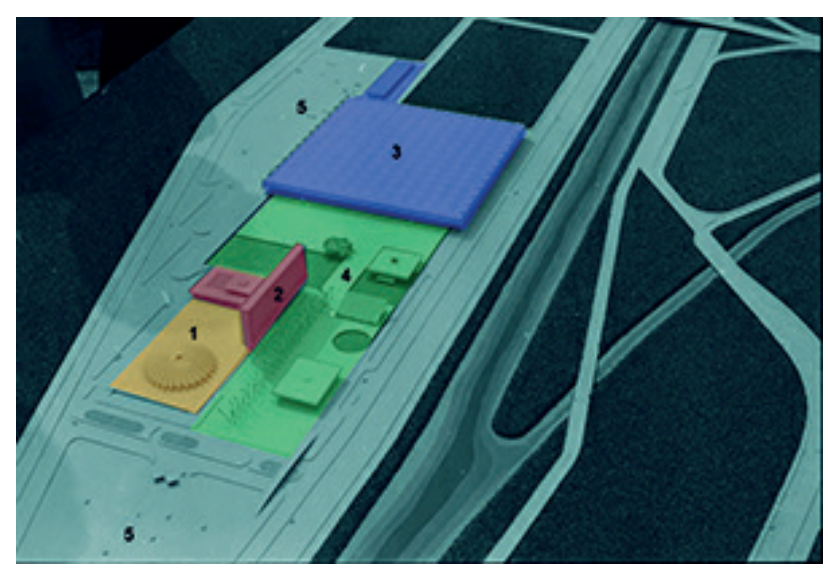

Fonte: Instituto Moreira Sales. 
No período de 1963 até 1972, vários foram os profissionais que atuaram no projeto. Juntamente com Miguel Juliano (1928-2009), principal colaborador do escritório Jorge Wilheim Arquitetos Associados desde a elaboração do anteprojeto e integrante da viagem à Montreal em 1967 para a definição da treliça espacial do Pavilhão de Exposições, estavam o matemático consultor da Alcan, Cedric Marsh (1924-2013), - qual faria os cálculos dessa estrutura; os projetistas Massimo Fiocchi, Suely Suchodolsky e Carlos Faggin; os estagiários Minor Suganuma, Francisco Miranda e Rafael (?); além do engenheiro mecânico Jairo Lisboa (1924), que traduziria os cálculos de Marsh em peças da produção, e do engenheiro calculista especialista em concreto armado Mario Franco (1929).

Além desses profissionais, cabe destacar as contratações dos projetos complementares que situam as propostas, cada qual nas suas especificidades mas dentro da escala urbana do projeto, de forma que é possível entender este conjunto de desenhos que direcionam o Parque Anhembi como parte pertencente a um todo que é a cidade, ou como possibilidade de ensaio para o experimento da atuação em outras áreas urbanas (OLIVEIRA, 2016). São eles: o projeto paisagístico de Roberto Burle Marx (1909-1994); projetos da área do design e comunicação, como o projeto de iluminação desenvolvido por Livio Levi (1933-1973); a adoção de alguns mobiliários projetados por Sergio Rodrigues (1927-2014); o projeto de sinalização e mobiliário urbano realizado pelo escritório de Ludovico Martino (1933) e João Carlos Cauduro (1935); e até mesmo a proposta de Décio Pignatari (1927-2012) na criação de um topônimo no nome do complexo.

Percebe-se, no geral, um entendimento fragmentado do conjunto do Parque Anhembi, bem como uma visão sumária da historiografia ou pesquisas sobre o conjunto, pois o que chama a atenção de fato nestas publicações são as experiências formais e técnico-construtivas adotadas de forma fragmentada: na cobertura do Pavilhão de Exposições, por se tratar de um exemplo experimental de outro processo de produção muito diverso daquele recorrente na arquitetura de até então; e na cobertura do Auditório do Palácio das Convenções em concreto armado, material familiar a outras obras da arquitetura paulista e que tinha uma relação específica com a engenharia e o cálculo estrutural na sua definição formal, sem falar de outras aproximações, como o vocabulário adotado por essa geração na medida em que se pretendia compreender a forma de ocupação espacial, as escolhas formais obtidas para responder problemas de composição monumental, além das soluções encontradas para solucionar as transições entre as áreas públicas e privadas.

$\mathrm{Na}$ verdade, há um mundo de articulações envolvido na adoção de cada um destes sistemas construtivos, tornando-as muito específicas, mas que convivem no mesmo recorte temporal. Para dar diferente ênfase ao objeto de estudo e aos valores a ele atrelados corriqueiramente nas discussões atuais, é importante entender certas escolhas dentro das facilidades encontradas nas articulações de outros interesses e agentes, como é o exemplo da relação da adoção da cobertura de alumínio do pavilhão com a indústria do alumínio pelo mercado mundial da construção civil.

O Brasil e provavelmente este projeto do pavilhão do Parque Anhembi seriam como uma porta de entrada da difusão do uso do alumínio, da tecnologia e do conhecimento técnico do sistema estrutural ainda não difundido no país e na América Latina, reforçando também a possibilidade de uma cultura projetual construtiva associada à produção industrial do alumínio. Da mesma forma como aconteceu na história da siderurgia brasileira, observa-se que, do projeto até o produto final, há uma convivência da importação da tecnologia, da assessoria estrangeira e da pesquisa tecnológica desenvolvida por técnicos brasileiros e que tem como resultado minúcias 
do desenho das peças e do cálculo estrutural jamais repetidas em outro projeto no Brasil. As peças da treliça espacial, por exemplo, foram projetadas para terem igual resistência em todos os pontos, razão esta que trouxe a diferenciação nos diâmetros e espessuras das barras, conforme os esforços solicitantes da localização de cada uma.

Segundo Jairo Lisboa', foram usadas duas ligas de alumínio, uma de alta resistência mecânica, considerada liga "estrutural", e outra liga, chamada de liga "arquitetural" (frequentemente empregada em caixilhos). Onde havia tração, utilizou-se a liga "arquitetural", mais simples e econômica, geralmente composta por tubos menores, de $80 \mathrm{~mm}$ ou $100 \mathrm{~mm}$, e que, na verdade, contemplam a maior parte dos tubos utilizados na cobertura do Pavilhão de Exposições. Os tubos de $120 \mathrm{~mm}$ e $150 \mathrm{~mm}$ são aqueles de liga "estrutural" e foram utilizados apenas nas áreas críticas, ou seja, nas áreas onde aparecem os esforços de compressão, graças à tendência de levantamento da cobertura por sua aerodinâmica favorável.

Desta forma, os tubos considerados estruturais foram usados em pequena quantidade, apenas onde seria necessário. Confiança no cálculo preciso jamais repetido posteriormente em qualquer outra estrutura espacial, segundo o próprio engenheiro Jairo Lisboa. A distribuição espacial das tensões levou em conta as regiões de sucção e compressão da cobertura, e desta forma foi possível antever o dimensionamento de cada um dos 10 tipos de barras projetadas para a cobertura.

Neste processo de definição do projeto, percebe-se que houve total liberdade no detalhamento da estrutura de alumínio, mesmo que no país não houvesse os produtos disponíveis no mercado, muito menos a produção desses elementos em escala. Houve, então, uma "condição ideal", uma vez que todas as minúcias técnicas idealizadas pelo calculista no projeto foram acatadas e produzidas.

Fig. 6. Planta das etiquetas de identificação das barras conforme a liga, espessura e comprimento. Alcan Alumíni do Brasil - Engenharia de desenvolvimento de produtos e vendas. Agosto, 1968.

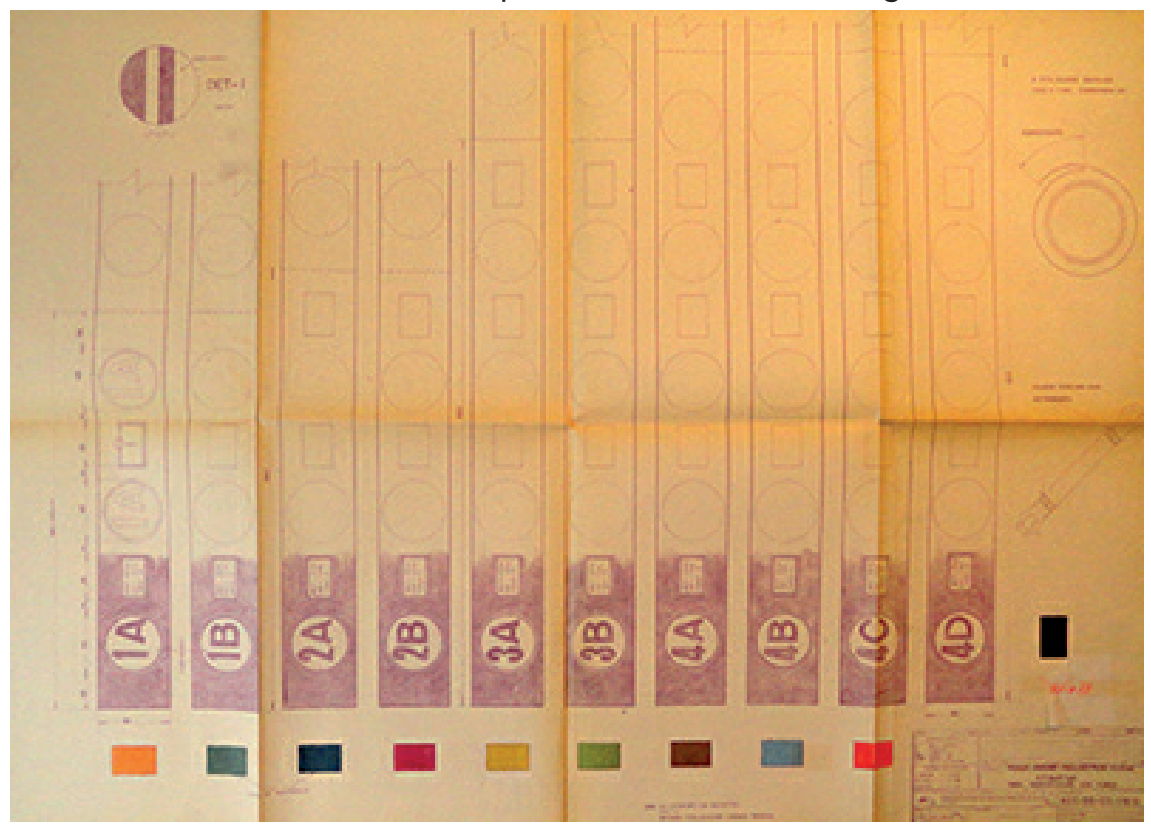

Fonte: Diretoria de Infraestrutura da São Paulo Turismo.

1 Em entrevista realizada pela autora deste artigo, em maio de 2012. 
Também foi produzida uma diversidade de elementos para a realização do projeto da estrutura geral, como tubos de diferentes especificações com dobras (estampagem), tubos de drenagem, chapas diversas, telhas, calhas, elementos de ligação ou mesmo de acabamento, rufos, caixilhos, etc., formando uma família de produtos de alumínio prontos para entrarem no mercado da construção civil no país. O sistema estrutural e seu domínio técnico foram também incorporados pelos técnicos brasileiros responsáveis por traduzir o cálculo em elementos passíveis de realização pela nossa indústria do alumínio ainda em expansão.

Também nesta etapa houve a livre tramitação entre os técnicos de São Paulo e da Alcan em Montreal e vice-versa. As determinantes que permitiram a excelência técnica do projeto da estrutura do pavilhão do Parque Anhembi, na realidade, tinham um forte interesse político e econômico. Alguns dados são relevantes para entender as motivações da execução do projeto. Segundo o Informativo Anhembi de 1969, a contratação do calculista Cedric Marsh foi feita pela Alcan Alumínio do Brasil, portanto se conclui que a empresa fornecedora do material tinha interesses em realizar o pavilhão ao patrocinar o técnico responsável pelo projeto. Há que se considerar também que os agentes envolvidos na contratação do projeto da estrutura em alumínio do pavilhão, Jorge da Rocha Fragoso e Raymundo de Campos Machado (primeiro e segundo vice-presidente da Alcan do Brasil), estavam também envolvidos com as promissoras pesquisas sobre as reservas comerciais de bauxita na Amazônia, as quais tinham sido confirmadas em 1967.

Em 1969 a Alcan anunciou a implantação do projeto de mineração no Rio Trombetas e a empresa Mineração Rio do Norte (MRN) foi organizada neste período para dirigir as pesquisas sobre a bauxita. Essa empresa era conduzida pela equipe jurídica paulista da matriz da Alcan no Brasil, tendo o engenheiro Jorge Fragoso como diretor e Raymundo de Campos Machado como presidente.
O principal objetivo da empresa era dar apoio à exportação de minério para o Canadá, mas não se deve deixar de lado que o governo federal vinha incentivando a ampliação da mineração de grande porte no país. Não é irrelevante que exatamente neste período o material estivesse sendo experimentado no mercado mundial da construção civil, juntamente com a aplicação dos cálculos das estruturas espaciais, numa briga internacional da indústria do alumínio, controlada basicamente por dois grandes grupos formados na década de 1920: a Aluminum Company of America e quatro membros da International Aluminum Cartel. Portanto, tanto as reservas dos outros países como o mercado interno nacional eram interesses desta disputa (LOUDON, 2009).

Fig.7. Da esquerda para a direita: Jorge da Rocha Fragoso, vice-presidente da Alcan; Jorge Luiz de Moras Dantas, diretor-superintendente do CIFS, e Raymundo de Campos Machado, vice-presidente da Alcan.

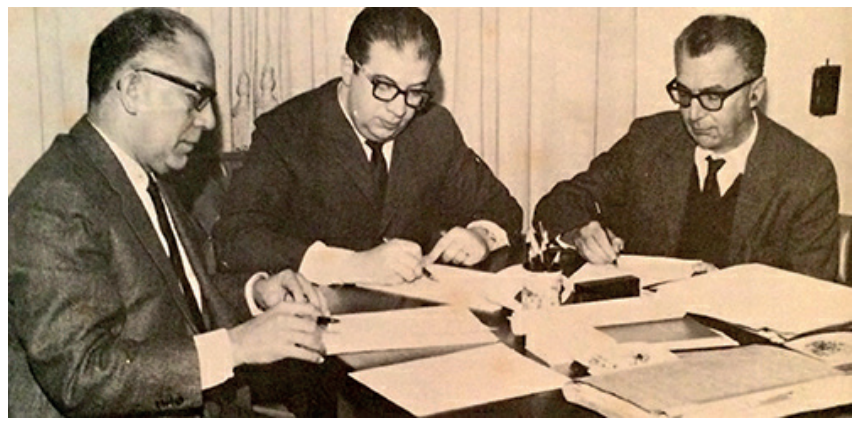

Fonte: CIFS. Assinados os contratos de estrutura e cobertura. In: Informativo Anhembi, n. 2, março de 1969, contracapa.

Muito mais que a economia do material e, consequentemente, a vontade de redução de custo ou peso, a implantação da cobertura em alumínio indica a maneira como a arquitetura e sua história podem contribuir para o entendimento de outras histórias, revelando as articulações de agentes interessados em financiar certos processos, as tramas dos acontecimentos daquele determinado momento histórico, político, social, econômico e cultural. Esse exemplo é apenas um caso específico de análise aqui empreendido, porém há outras tramas que apontam esse conjunto como importante documento material 
dessas histórias. E essa discussão se reveste de um olhar mais apurado ainda quando cada procedimento envolvido e cada nível de produção existente nesses fragmentos analisados (pré-fabricação, industrialização e manufatura) são justapostos na visão do conjunto novamente.

Não se pode deixar de lembrar da escala urbana do conjunto, e não apenas como um discurso isolado, mas como um interesse de produção e reprodução do espaço urbano. Esta condição não pode ser anedótica na análise pretendida, e então a questão volta-se para a totalidade do conjunto, tentando-se compreender como se deu a sobreposição dos níveis de produção no projeto, principalmente, dentro do canteiro de obras, evidenciando, assim, as diferenças, contradições e mecanismos de compensação. A "eficiência" divulgada em parte do processo, na estrutura metálica, na verdade consumiu boa parte do que seria investido no restante do conjunto, pois o que se sabe é que o conjunto Palácio-Hotel acabou sendo prejudicado (e nem se fale do restante do projeto, como a praça, que nunca mais foi pauta de reivindicações). Sem tribuna para manifestações, quem financiou a construção do Pavilhão de Exposições foi a generosa fatia do imposto de renda embrulhada nas imagens do espaço urbano que ele vendia na grande mídia; na mão de obra barata utilizada no canteiro extensivo e desqualificado do Palácio-Hotel; no cálculo preciso e «no limite» do desenho da cobertura em concreto armado do auditório do Palácio das Convenções.

Dessa forma, é fato afirmar que a sobreposição dos sistemas construtivos e dos níveis de produção no Parque Anhembi significou menos uma "pluralidade" da produção arquitetônica efetivamente (como identifica os manuais de historiografia da arquitetura do período) e mais um mecanismo de deslocamento. Porque foi funcional existir atraso em parte do processo, era necessário haver uma reserva. A reserva do custo do terreno, a da aplicação dos materiais da indústria, a de mercados e matérias-primas ainda não explorados, a reserva da mão de obra do canteiro do Palácio das Convenções, a reserva do espaço público que nunca se concretizou e que 40 anos depois nunca foi reivindicado. Porque a necessidade era de uma infraestrutura técnica moderna no território que elevasse São Paulo ao maior destino turístico, comercial e empresarial do país. E foi isso o que ocorreu. Porém as contradições do nosso desenvolvimento continuam praticamente da mesma forma, exploratória, conforme - Parque Anhembi pode demostrar ainda hoje nos meios de montagem e desmontagem das grandes feiras, por exemplo - assunto ainda pouco explorado e renegado.

Assim, olhar para esse projeto necessariamente obriga a ultrapassar a noção de autoria individual e se aprofundar nas colaborações de cada agente, dentre eles a equipe técnica de arquitetos, projetistas, engenheiros, empresas consultoras, construtoras, empresas e escritórios terceirizados ou especializados, empresários da construção civil, promotores das feiras, Estado, obreiros, etc., de modo a reconstruir um desenho dessas conexões sociais que se mostravam ora mais ora menos estabelecidas nesse período. Nesse mergulho, ficam manifestos momentos de afirmação ou negação de certas características da arquitetura moderna pós1960, ou mesmo de construção e desconstrução dos discursos dos próprios arquitetos sobre este período exposto pela historiografia.

É possível, então, apontar para algumas dissoluções de cânones da análise historiográfica, abrindo caminhos para outras leituras, fontes documentais, novos atores, outros processos e linhas de atuação, questionando suas interpretações já reconhecidas. Abre-se, então, espaço para outra leitura, principalmente para as discordâncias e o contraditório, coexistência de opostos ou mesmo a afirmação de outros meios de entendimento das pluralidades envolvidas (TAFURI, 2011). E essas escalas de análises vão ganhando tamanha complexidade e dimensão que na realidade vêm contribuir para uma mudança de posição frente ao passado, inclusive do ponto de vista do que a história pode oferecer de ferramentas para a investigação da materialidade da arquitetura, estimulando 
também o entendimento das questões do presente e, consequentemente, a formulação de novas perguntas em face dos problemas atuais. Mais relevante ainda é o objetivo dessas análises diante do desafio de investigação historiográfica ao construir conexões com outras histórias, especialmente com a história da técnica, do trabalho, da economia, da política e da cultura.

\section{Valores patrimoniais e a necessidade de testemunhos vivos}

Em outubro de 2016, o prefeito de São Paulo, João Doria, anunciaria a privatização do Parque Anhembi no meio de outros equipamentos públicos da cidade, mas o tema ganhou pauta quando o processo de tombamento do conjunto ganhou velocidade dentro do Conpresp a fim de uma definição precisa naquele ano sobre a sua efetiva privatização, em 2017. O processo de tombamento caminhava a passos lentos desde 2004, e o seu teor, segundo Silvio Oksman, já tinha o entendimento da leitura de conjunto sugerida até aqui:

O processo de tombamento do Anhemb foi aberto em 2004, apresentando várias camadas sobrepostas de leitura do conjunto: as soluções de arquitetura e engenharia - inovadoras e inéditas do ponto de vista espacial e construtivo; a importância dos edifícios como marco na paisagem da cidade numa de suas principais vias de acesso, a Marginal do Tietê; e também o significado do conjunto dentro das atividades econômicas de São Paulo. (OKSMAN, 2017.)

É possivel que a definição mais precisa sobre o valor desse conjunto no âmbito da sua escala do conjunto e das suas relações com outras histórias que caracterizariam o período por que passaram São Paulo e nosso país tenha sido afirmada com mais precisão após a divulgação da tese de doutoramento em 2016, apresentada ao Conpresp em 2017. Talvez esse processo pudesse ter sido levado adiante com os devidos cuidados caso fosse possível avaliar cada parcela de defesa deste tombamento hoje, quando temos mais elementos de análise e justificativas sobre o valor atribuído ao conjunto.

Essa é uma discussão que poderia gerar bons frutos caso houvesse tempo e caso ocorresse numa ocasião diversa daquele momento de pressão imobiliária - já que este governo representa esses interesses com bastante nitidez. E certamente a consciência desses valores a serem preservados e evidenciados neste documento material foi entendida por todos os envolvidos e interessados pela privatização do conjunto (até porque a própria tese é citada no parecer técnico), porém em nenhum momento ela poderia sensibilizá-los. Fica evidente o significado do instrumento do tombamento como forma antagônica à valorização do imóvel pelo mercado e pela atual gestão: "Tombamento do Anhembi ameaça plano de privatização" (FSP, 2017) anunciavam os jornais.

O tom "ameaçador" sobre a possibilidade do tombamento que ressoou em todos os veículos de comunicação demonstrou abertamente o entendimento dos nossos meios de salvaguarda, principalmente do instrumento do tombamento, como inibidores de novos usos e investimentos ou mesmo da sua possibilidade de burocratização. Era necessário criar, então, alguma justificativa convincente para levar ao arquivamento do processo e responder ao interesse da privatização. E essa justificativa pôde ser qualquer coisa sem sentido para quem é qualificado no assunto, mas significou - pior precedente que se poderia abrir para as políticas de preservação no Brasil, uma vez que afirma com todas as letras a dispensa de nossos bens materiais no cotidiano da cidade e na paisagem urbana, conforme a transcrição do parecer técnico do Conselho durante a decisão do seu indeferimento indica:

Outrossim consideramos que a importância histórica e cultural do bem já está amplamente garantida através da preservação dos projetos de engenharia e que encontram-se na empresa SPTuris. Consignamos que a própria tese de 
doutoramento já produz todos os efeitos relativos à preservação da história deste equipamento bastante importante e que de tal forma já contribui para entrar nos anais desta cidade e dos órgãos de preservação. Dessa forma encaminhamos o nosso voto pelo não tombamento do bem. (OLIVEIRA, 2017.)

Conforme Silvio Oksman (2017) aponta, cria-se um antecedente grave, pois a mesma lógica de substituição da cidade por documentos pode se tornar natural e crescente em até casos de destombamentos. A isso tudo se soma uma série de outros pormenores que ainda não se sabe com firmeza aonde podem chegar, mas que de fato podem silenciar de forma providencial qualquer possibilidade de debate dentro das inevitáveis divergências existentes entre os interesses e formas de representação na cidade que até então nos aparecia possível.

Foi um momento de grande tensão quando então os arquitetos manifestaram abertamente as suas indignações, técnicos no conselho de defesa do patrimônio desligaram-se das suas funções, cartas abertas foram publicadas pelo instituto de representação de classe, artigos inflamados foram publicados em jornais de grande circulação - chegando-se ao ponto de verdadeiras denúncias sobre a manipulação ideológica dos representantes da sociedade nos nossos órgãos de preservação. Parece inquietante que a indignação não acometeu outros campos fora dos interesses disciplinares, dificultando, então, um enfrentamento mais intenso sobre o problema e configurando como urgente a necessidade de uma avaliação e ação por parte de toda a sociedade.

Mas o que é certo neste momento é o desejo do apagamento da história do Parque Anhembi e dessa memória recente do país reveladora dos mecanismos usados para defender os interesses do empresariado na gestão da cidade. As tramas discorridas pela pesquisa acadêmica mostram as mesmas manipulações vistas agora e que não mais escondem as situações exploratórias em seus diversos níveis, inclusive na tomada para si de bens públicos, desde que sejam rentáveis e até que sejam rentáveis.

\section{Referências}

BRASIL. Decreto Lei 55, novembro de 1966.

BETING, Joelmir. Parque Anhembi. In: Folha de

S. Paulo. São Paulo, 23 de maio de 1970.

DEDECCA, P. G. Sociabilidade, crítica e posição: o meio arquitetônico, as revistas especializadas e o debate do moderno em São Paulo (19451965). Dissertação de mestrado, FAU USP: São Paulo, 2012.

FERRO, Sergio. O canteiro e o desenho. In: Arquitetura e trabalho livre. São Paulo: Cosac Naify, 2006. (Publicado originalmente em 1976 na revista Almanaque e no livro $O$ canteiro e o desenho. São Paulo: Projeto, 1978).

FOLHA DE S. PAULO. Tombamento do Anhembi ameaça plano de privatização. In: Nas ruas, UOL, 30 de outubro de 2017. Disponível em: <http://www.agora.uol.com.br/saopaulo/2017/10/ 1931382-tombamento-do-anhembi-ameaca-plano-de-privatizacao.shtml>. Acesso em: 10 fev. 2018.

GIEDION, Siegfried. "Le Brésil et l'architecture contemporaine". L'architecture d'au jourd'hui, agosto de 1952.

JOTA PRODUÇÕES. Anhembi: sinal verde. São Paulo, 1970.

LOUDON, D. S; COLLINS JR., Morgan. The aluminum industry. In: Harvard Business Review, maio, 2009.

OKSMAN, Silvio. Parque Anhembi. Vale a pena preservar? In: Minha Cidade, São Paulo, ano 18, n. 209.02, Vitruvius, dez. 2017. Disponível em: <http://www.vitruvius.com.br/revistas/read/minhacidade/18.209/6808>. Acesso em: 10 jul. 2018.

OLIVEIRA, R. C. de. A escala urbana do projeto do Parque Anhembi e o trabalho coletivo (1963-1972). In: Anais do $11^{\circ}$ seminário nacional do DOCOMOMO BRASIL. Recife: DOCOMOMO_BR, 2016.

Parque Anhembi: a produção de um centro de exposições em São Paulo (1963-1972.) Tese de Doutorado. FAU USP, São Paulo, 2016. 
Transcrição da reunião ordinária

do Conpresp, São Paulo, 30 de outubro de 2017. PEDROSA, M. Das arquiteturas e de suas críticas. In: AMARAL, A. (org.) Mario Pedrosa: dos murais de Portinari aos espaços de Brasília. São Paulo: Perspectiva, 1981, p. 405.

REVISTA VEJA. O tamanho de um gigante: $O$ parque Anhembi e seu criador. Edição 114, de 11 de novembro de 1970.

SANTOS, Milton. Salvador: centro e centralidade na cidade contemporânea. In: GOMES, Marco Aurélio A. de Figueiras (org.). Pelo Pelô: história, cultura e cidade. Salvador: Editora da Universidade Federal da Bahia, 1995, p. 18.

SPTURIS. Entrevista com Caio de Alcântara Machado. São Paulo, 1990.

TAFURI, Manfredo. Arquitetura e Historiografia. Uma proposta de método. Desígnio: revista de história da arquitetura e do urbanismo. FAU USP. São Paulo: Annablume; FAU USP, 2011 - n. 11/12 (mar. 2011), pp. 19-28.

WILHEIM, Jorge. São Paulo: metrópole 65. São Paulo: DBA, Artes Gráficas, 2003. 